\title{
Review Article \\ Efficacy and Safety of Medicinal Plants or Related Natural Products for Fibromyalgia: A Systematic Review
}

\author{
Simone de Souza Nascimento, ${ }^{1}$ Josimari Melo DeSantana, ${ }^{2}$ Fernando Kenji Nampo, \\ Êurica Adélia Nogueira Ribeiro, ${ }^{3}$ Daniel Lira da Silva, ${ }^{3}$ João Xavier Araújo-Júnior, ${ }^{3}$ \\ Jackson Roberto Guedes da Silva Almeida, ${ }^{4}$ Leonardo Rigoldi Bonjardim, ${ }^{5}$ \\ Adriano Antunes de Souza Araújo, ${ }^{1}$ and Lucindo José Quintans-Júnior ${ }^{1}$ \\ ${ }^{1}$ Department of Physiology, Federal University of Sergipe, Marechal Rondom Avenue, 49000-100 São Cristovão, SE, Brazil \\ ${ }^{2}$ Collegiate of Physical Therapy, Federal University of Sergipe, Cláudio Batista Street, 49060-100 Aracaju, SE, Brazil \\ ${ }^{3}$ Department of Nursing and Pharmacy, Federal University of Alagoas, Lourival de Mello Motta Avenue, 57072-970 Maceió, AL, Brazil \\ ${ }^{4}$ Department of Pharmaceutical Sciences, Federal University of São Francisco Valley, José de Sá Maniçoba Avenue, \\ 56304205 Petrolina, PE, Brazil \\ ${ }^{5}$ Department of Biological Sciences, Bauru School of Dentistry, University of São Paulo, Octávio Pinheiro Brisola Street, \\ 17012-901 Bauru, SP, Brazil
}

Correspondence should be addressed to Lucindo José Quintans-Júnior; lucindojr@gmail.com

Received 1 April 2013; Accepted 14 May 2013

Academic Editor: Cayetano Alegre

Copyright ( 2013 Simone de Souza Nascimento et al. This is an open access article distributed under the Creative Commons Attribution License, which permits unrestricted use, distribution, and reproduction in any medium, provided the original work is properly cited.

\begin{abstract}
To assess the effects of medicinal plants (MPs) or related natural products (RNPs) on fibromyalgia (FM) patients, we evaluate the possible benefits and advantages of MP or RNP for the treatment of FM based on eight randomized placebo-controlled trials (RCTs) involving 475 patients. The methodological quality of all studies included was determined according to JADAD and "Risk of Bias" with the criteria in the Cochrane Handbook for Systematic Reviews of Interventions 5.1.0. Evidence suggests significant benefits of MP or RNP in sleep disruption, pain, depression, joint stiffness, anxiety, physical function, and quality of life. Our results demonstrated that MP or RNP had significant effects on improving the symptoms of FM compared to conventional drug or placebo; longer tests are required to determine the duration of the treatment and characterize the long-term safety of using MP, thus suggesting effective alternative therapies in the treatment of pain with minimized side effects.
\end{abstract}

\section{Introduction}

Fibromyalgia (FM) is an example of rheumatologic disease that leads to chronic musculoskeletal pain diffuse, usually associated to fatigue, sleep disruption, mood disorders, and depression, among other symptoms. Although its pathogenesis is not fully understood, most of the evidence points to either a disorder in the central pain modulation or an alteration in the processing of the central nervous system in response to a noxious stimulus [1-5].

Many therapeutic approaches are sought by patients to control symptoms of FM. Pharmacologic therapy is one of the resources used in the treatment of chronic pain. Among the most widely used drugs are opioids, nonsteroidal anti-inflammatory drugs (NSAIDs), muscle-relaxing medications, painkillers, and peripheral antidepressants [6]. However, 40 to $60 \%$ of patients do not respond well to drug therapy $[7,8]$. For this reason, the search for novel therapies remains constant throughout the world [9].

A current approach is to develop a new biological compound from natural products that inhibits pain, such as MP or its secondary metabolites, with enhanced efficacy and minimal side effects $[10,11]$. Butler (2008) [11] conducted an extensive research on the drugs approved by the Food and 
Drug Administration (FDA, USA) in the last decade and described that about $40 \%$ of new drugs originate from natural products. Although the application of medicinal plants in treatments around the world has suffered a strong advance, there are still a few studies that prove the safe and effective use of various plants [12]. Notable progress has been made in the recent years in the development of natural therapies, but there is an urgent need to discover effective and potent analgesic agents [13].

As the evidence-gathering tools, systematic reviews (SRs) of randomized controlled trials (RCTs) are considered to provide the best evidence about the effectiveness of interventions [14]. Therefore, the aim of this systematic review was to examine the clinical evidence on the use of medicinal plants for FM based on RCTs of herbal preparations against all control treatments or standard treatment, emphasizing treatment evidence and promising responses in the literature. We believe it is useful to assess the quality of these studies and to evaluate the efficacy and safety of the data provided by the tests in terms of principles and measures of evidence-based medicine.

\section{Methods}

2.1. Search Strategy for the Identification of Studies. A computerized search in three electronic databases and the hand search performed by reviewing the references of the included articles resulted in nine studies meeting the inclusion criteria. Two raters independently extracted data and rated the trials for quality. The following electronic databases were assessed (performed between November/2012-January/2013) for publications dated between 1964 and December/2012: Medline, Embase, and Scopus. Free text searches were performed across each database to combine the terms or key words: "fibromyalgia" and "medicinal plants" and "treatment." The general structure of the search strategy was "fibromyalgia" with the following MeSH terms or synonyms: (Fibromyalgias) OR (Fibromyalgia-Fibromyositis Syndrome) OR (Fibromyalgia Fibromyositis Syndrome) OR (Fibromyalgia, Primary) OR (Fibromyalgias, Primary) OR (Primary Fibromyalgia) OR (Primary Fibromyalgias); "Plants, medicinal" MeSH terms or synonyms were: (Medicinal Plant) OR (Plant, Medicinal) OR (Medicinal Plants) OR (Medicinal Herbs); and "Treatment" MeSH terms or synonyms were (Outcome, Treatment) OR (Treatment Effectiveness) OR (Effectiveness, Treatment) OR (Treatment Efficacy) OR (Efficacy, Treatment).

2.2. Inclusion and Exclusion Criteria. RCTs comparing herbal preparations versus placebo or other drugs administered either orally or topically in the treatment of patients with FM were included. At least one of the outcomes should be pain, sleep, quality of life, physical function, or anxiety. Only papers in English were included. We excluded case reports, researches on acupuncture, moxibustion, cupping, and articles on complementary or alternative medicine (CAM) therapies that did not include plants in their comments and literature reviews.
2.3. Data Extraction, Quality Assessment, and Risk of Bias. All articles were read, and data were extracted from the articles based on predefined selection criteria by two independent reviewers. The methodological quality of the included RCTs was evaluated by using both JADAD scale [23] and the "Risk of Bias table" recommended by Cochrane Collaboration [24].

\section{Results}

3.1. Studies Description. The literature search yielded 252 results and 220 were excluded, leaving us with 32 eligible full-text articles. Out of these, 24 more were excluded and eight RCTs remained (Figure 1). Characteristics of included studies and quality assessment according to JADAD quality scale [23] are summarized in Table 1. A placebo procedure was employed in all eight trials [15-22].

The ratio of male/female participants in five studies was 19/202. Three studies $[16,17,21]$ did not report gender distribution. A total of 475 subjects were included in the eight studies. The ages of the patients were 18-79 years and the average size of the trials was 29-133 participants.

The inclusion criteria for FM in all studies reviewed were the diagnostic criteria for FM, established in 1990 by the American College of Rheumatology and actualized for Wolfe et al. (2010) [25], which includes widespread pain for at least three months and tender point with $4 \mathrm{~kg}$ of pressure at 11 or more of 18 characteristic sensitive points [26-28].

Five interventions were administered orally [17, 18, 20$22]$ and three topically $[15,16,19]$. The duration of study varied from one day to twelve weeks, one to four times per day. The sample size also varied from 29 to 133, totaling 475 patients.

The main variables measured are related to the signs and symptoms of fibromyalgia. As measured results, the pain was assessed in all studies, with significant pain intensity reduction in five of those studies $[15,16,18,21,22]$. Other variables were assessed: quality of life $[17,18,22]$, physical performance [20], anxiety [21], and sleep disturbance [22]. All variables were measured using internationally validated instruments (Table 1).

Adverse effects related to the use of plants in FM patients included transient burning and pricking at the application site [18], dizziness, nausea, dry mouth, drowsiness, constipation, insomnia [15], skin irritation [20], moderate transient stinging, or burning at the application sites, which generally decrease or disappear throughout the treatment.

The most common reasons for withdrawal, dropout, and/or loss during followup were personal reasons or adverse events $[15-18,22]$ and stigma associated with the use of cannabinoids or previous oral use [21]. Other studies did not report the reasons for discontinuation of treatment $[19,20]$.

3.2. Risk of Bias in Included Studies. The methodological quality of each study is summarized following Cochrane Handbook recommendation [24]. Author's judgment about 


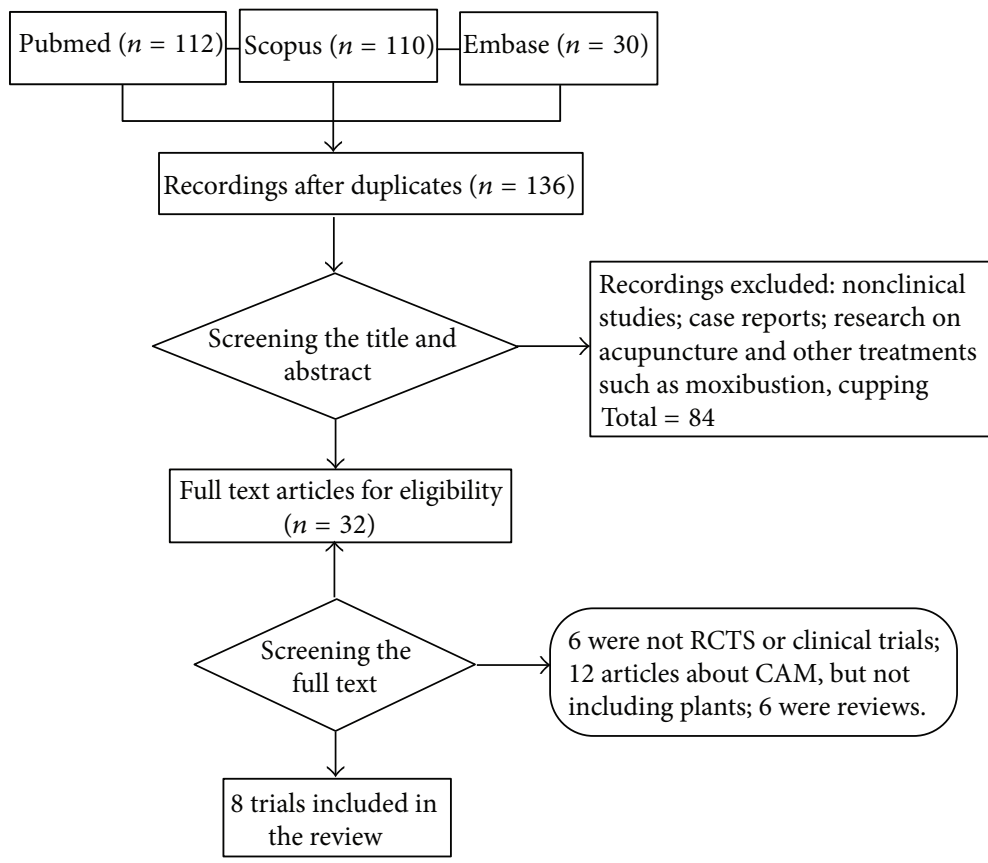

FIGURE 1: Flow diagram of the literature search.

"methodological quality" for each included study and percentages across all included studies are shown in Figures 2 and 3 , respectively.

Three studies [20-22] reported using a random number table, one study [15] reported using a computer-generated random-number table, another [16] reported using newspaper advertisements and internet communication to FM support groups, and three studies [17-19] used no allocation concealment and thus presented a high risk of selection bias.

Five studies [16, 19-22] were double-blinded; thus, these studies had a low risk of performance bias and low detection bias. The other three studies $[15,17,18]$ did not use blinding methods and had a high risk of performance bias or a strong detection bias.

No detailed evidence of selective reporting was found in any of the eight studies. As for other potential sources of bias, one study exhibited a patient compliance, which could suggest acceptance and applicability of the product.

3.3. Effects of Interventions. All studies compared MP or RNP basic therapy to standard treatment or placebo. The medicinal plants treatments included the Modified Meta050 [18], provided as a tablet containing $440 \mathrm{mg}$ of a proprietary formulation of RIAA (as magnesium salt from Humulus lupulus cone extract), standardized rosemary extract (Rosmarinus officinalis), and oleanolic acid (from Olea europaea olive leaf extract). Another treatment was coenzyme Q10 [17], provided in gelatine capsules and $100 \mathrm{mg}$ tablets of Ginkgo biloba standardized to contain $24 \mathrm{mg}$ flavone glycosides and $6 \mathrm{mg}$ terpene lactones (Bio-Biloba, pharma Nord). Among RNPs, two studies used nabilone [21, 22]; among MPs two used capsaicin $[15,19]$, and two used O24 [16, 20].

Two studies investigated the effects of topical capsaicin, a compound obtained from chili peppers (Capsicum annuum L.), in FM patients. An RCT tested the efficacy of the local application of $0.075 \%$ capsaicin in FM patients [15] compared with patients from the control group, who continued taking the usual treatment provided before randomization. At the end of the intervention, 108 patients were assessed for pain, which was related to other clinical outcomes: body mass index (BMI) and the number of physical symptoms, myalgic score, pressure pain threshold, pain, fatigue, anxiety, and depression. Capsaicin-treated patients showed improvement in myalgic score and in the end of the therapy patients of both groups presented a global subjective improvement that was defined as decrease in pain, improvement in physical function, and in sleep or fatigue. At the end of the followup, six weeks after capsaicin discontinuation, those who were treated with topical capsaicin still showed significant improvement in several clinical outcomes compared to controlsnamely, myalgic score, pressure pain threshold, FSS, FIQ, VAS of depression, and role limitations due to emotional problems.

Another double-blinded RCT [19] that investigated the effects of topical capsaicin tested the efficacy of the local application of $0.025 \%$ capsaicin in the treatment of FM, comparing with placebo cream and control group. Forty-five patients were randomly assigned, and after four weeks of doubleblinded treatment, they were assessed for pain, stiffness, and sleep disruption. Significant improvement of sensitivity and pain was associated to capsaicin. However, there was no improvement in pain or quality of sleep. 


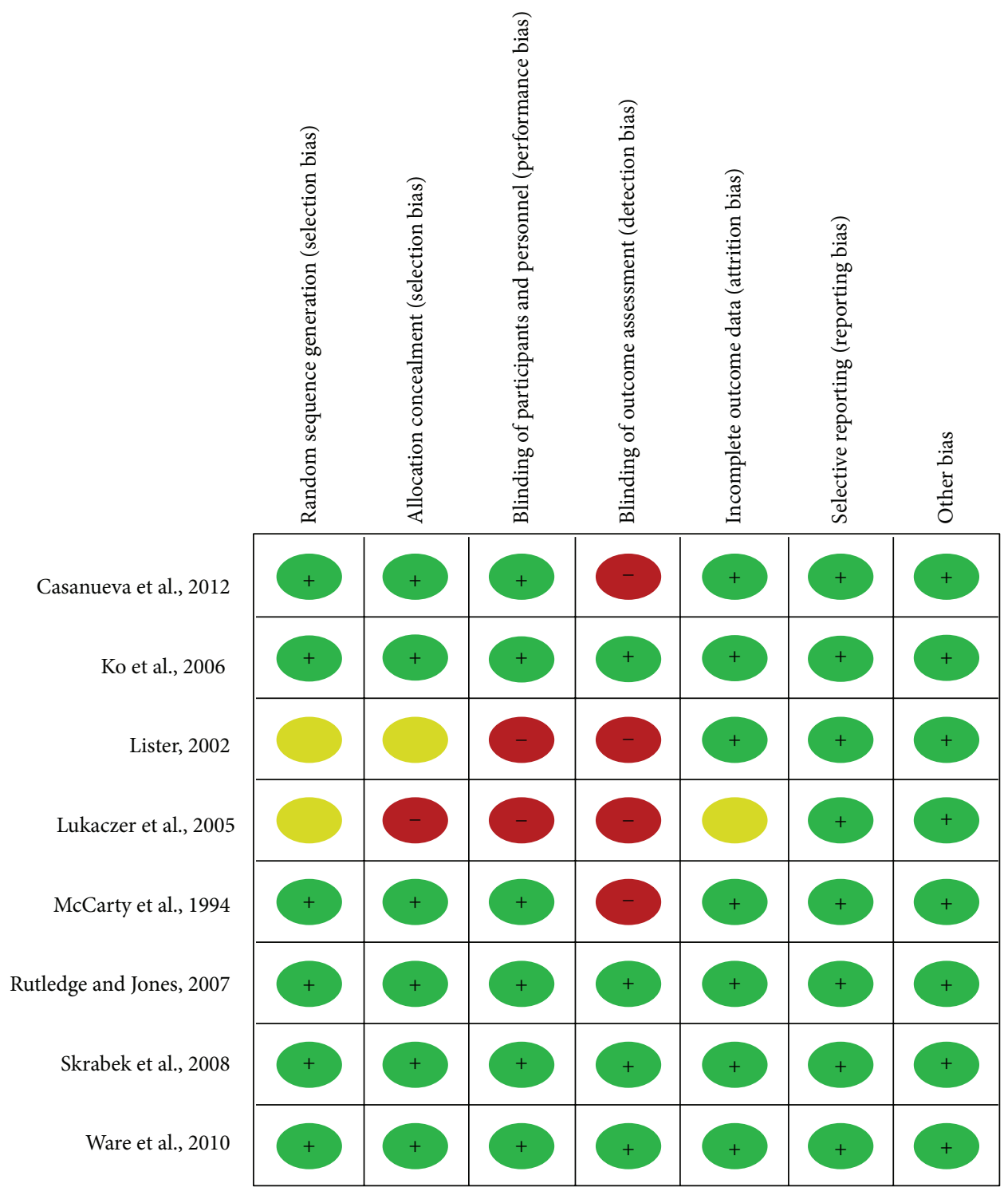

FIGURE 2: Risk of bias summary: review authors' judgments about each risk of bias item for each included study. Green: unclear risk of bias; yellow: uncertain risk of bias; red: high risk of bias.

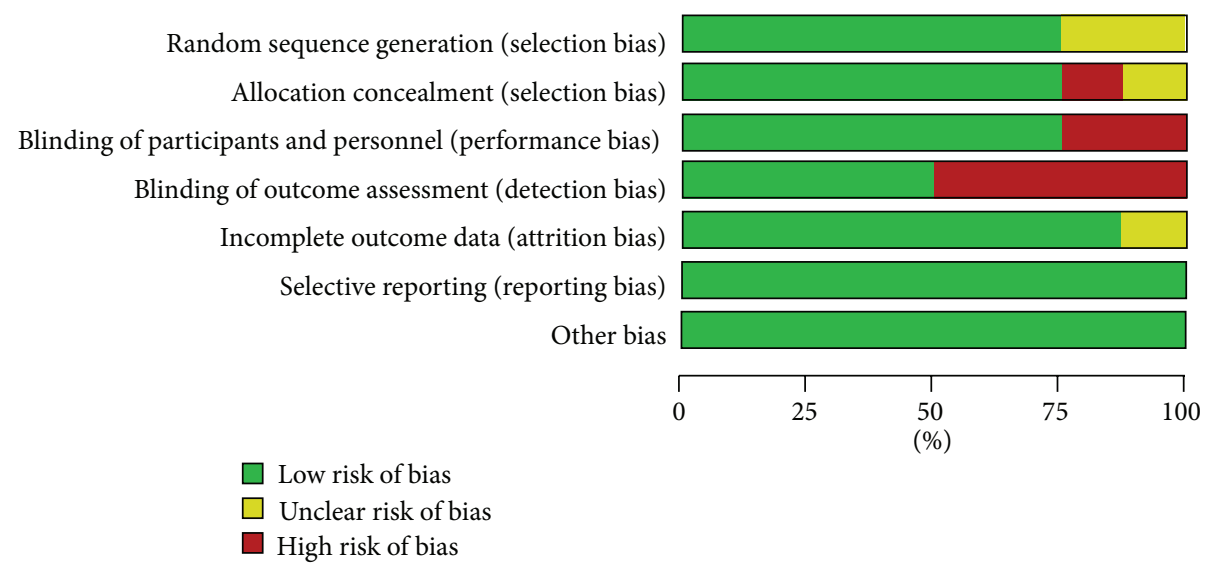

FIGURE 3: Risk of bias graph: review authors' judgments about each risk of bias item presented as percentages across all included studies. 
TABLE 1: Summary of randomized clinical studies of medicinal plants or related natural product in fibromyalgia.

\begin{tabular}{|c|c|c|c|c|c|c|c|c|}
\hline Reference/year & Plant/route & $\begin{array}{l}\text { Sample } \\
\text { size }\end{array}$ & $\begin{array}{c}\text { Duration of } \\
\text { study }\end{array}$ & $\begin{array}{l}\text { Outcome } \\
\text { measured }\end{array}$ & $\begin{array}{c}\text { Clinical } \\
\text { assessment } \\
\text { instrument }\end{array}$ & $\begin{array}{l}\text { Findings of the } \\
\text { study }\end{array}$ & Adverse effects & $\begin{array}{l}\text { Jadad } \\
\text { score }\end{array}$ \\
\hline $\begin{array}{l}\text { Casanueva } \\
\text { et al., } 2012 \text { [15] }\end{array}$ & Capsaicin/topical & 108 & 12 weeks & $\begin{array}{l}\text { Pain } \\
\text { Fatigue } \\
\text { Anxiety } \\
\text { Depression }\end{array}$ & $\begin{array}{c}\text { VAS } \\
\text { BPI } \\
\text { MPQ } \\
\text { FIQ } \\
\text { FSS }\end{array}$ & $\begin{array}{l}\text { Significant } \\
\text { improvement in } \\
\text { pain, } \\
\text { depression, } \\
\text { fatigue }\end{array}$ & $\begin{array}{l}\text { Transient } \\
\text { burning and } \\
\text { pricking }\end{array}$ & 5 \\
\hline $\begin{array}{l}\text { Ko et al., } 2007 \\
{[16]}\end{array}$ & Oil 24/topical & 133 & one month & $\begin{array}{l}\text { Pain } \\
\text { Subjective } \\
\text { surveys of pain } \\
\text { Measurements } \\
\text { of tender point }\end{array}$ & $\begin{array}{l}\text { VAS } \\
\text { FIQ } \\
\text { FDK } 10 \\
\text { TePs }\end{array}$ & $\begin{array}{l}\text { Significant } \\
\text { improvement in } \\
\text { surveys of pain } \\
\text { and in measures } \\
\text { of tender point }\end{array}$ & Skin irritation & 4 \\
\hline Lister, 2002 [17] & $\begin{array}{c}\text { Coenzyme } \\
\text { Q10 and Ginkgo } \\
\text { biloba/oral }\end{array}$ & 23 & 12 weeks & Quality of life & SF-36 & $\begin{array}{l}\text { Significant } \\
\text { improvement in } \\
\text { quality of life }\end{array}$ & $\begin{array}{l}\text { Little or no } \\
\text { clinical } \\
\text { significance }\end{array}$ & 1 \\
\hline $\begin{array}{l}\text { Lukaczer et al., } \\
2005 \text { [18] }\end{array}$ & Meta050/oral & 54 & 8 weeks & $\begin{array}{l}\text { Pain } \\
\text { Quality of life } \\
\text { Physical } \\
\text { function }\end{array}$ & $\begin{array}{c}\text { VAS } \\
\text { FIQ } \\
\text { SF-36 } \\
\text { PCS } \\
\text { MCS }\end{array}$ & $\begin{array}{l}\text { Significant } \\
\text { improvement in } \\
\text { pain }\end{array}$ & $\begin{array}{l}\text { No evidence } \\
\text { suggested }\end{array}$ & 1 \\
\hline $\begin{array}{l}\text { McCarty et al., } \\
1994 \text { [19] }\end{array}$ & $\begin{array}{c}\text { Due } \\
\text { capsaicin/topical }\end{array}$ & 45 & 4 weeks & $\begin{array}{l}\text { Pain } \\
\text { Tenderness } \\
\text { Stiffness }\end{array}$ & $\begin{array}{l}\text { FIQ } \\
\text { VAS } \\
\text { TePs }\end{array}$ & $\begin{array}{l}\text { Significant } \\
\text { improvement in } \\
\text { pain, } \\
\text { tenderness, and } \\
\text { stiffness }\end{array}$ & $\begin{array}{l}\text { Moderate } \\
\text { transient } \\
\text { stinging or } \\
\text { burning }\end{array}$ & 3 \\
\hline $\begin{array}{l}\text { Rutledge and } \\
\text { Jones, } 2007 \text { [20] }\end{array}$ & Oil 24/topical & 43 & 12 weeks & $\begin{array}{l}\text { Pain } \\
\text { Physical } \\
\text { performance } \\
\text { Exercise volume } \\
\text { Physical } \\
\text { function }\end{array}$ & $\begin{array}{l}\text { BPI } \\
\text { GSI } \\
\text { BMI } \\
\text { HGS } \\
\text { FDK }\end{array}$ & $\begin{array}{l}\text { Significant } \\
\text { improvement in } \\
\text { physical } \\
\text { function }\end{array}$ & $\begin{array}{l}\text { No evidence } \\
\text { suggested }\end{array}$ & 4 \\
\hline $\begin{array}{l}\text { Skrabek et al., } \\
2008[21]\end{array}$ & Nabilone/oral & 40 & 4 weeks & $\begin{array}{l}\text { Pain } \\
\text { Anxiety }\end{array}$ & $\begin{array}{l}\text { VAS } \\
\text { FIQ }\end{array}$ & $\begin{array}{l}\text { Significant } \\
\text { improvement in } \\
\text { pain and anxiety }\end{array}$ & $\begin{array}{l}\text { No evidence } \\
\text { suggested }\end{array}$ & 5 \\
\hline $\begin{array}{l}\text { Ware et al., } 2010 \\
{[22]}\end{array}$ & Nabilone/oral & 29 & 10 weeks & $\begin{array}{l}\text { Sleep disruption } \\
\text { Pain } \\
\text { Quality of life } \\
\text { Mood }\end{array}$ & $\begin{array}{c}\text { ISI } \\
\text { LSEQ } \\
\text { MPQ } \\
\text { SF-36 } \\
\text { FIQ } \\
\text { HADs-D }\end{array}$ & $\begin{array}{l}\text { Significant } \\
\text { improvement in } \\
\text { quality of sleep }\end{array}$ & $\begin{array}{l}\text { Dizziness } \\
\text { subjects, } \\
\text { nausea, dry } \\
\text { mouth, } \\
\text { drowsiness, } \\
\text { constipation } \\
\text { Insomnia }\end{array}$ & 4 \\
\hline
\end{tabular}

BMI: Body Mass Index. BPI: Brief Pain Inventory. FIQ: Fibromyalgia Impact Questionnaire. Force Dial FDK 40: Standard Pressure Algometry. FSS: Fatigue Severity Scale. GSI: Global Severe Index. HADs-D: Hospital Anxiety and Depression Scale. HGS: Handgrip Strength. ISI: Insomnia Severity Index (ISI); LSEQ: The Leeds Sleep Evaluation Questionnaire. MCS: Mental Function Score. MPQ: The McGill Pain Questionnaire. PCS: Physical Function Score. SF-36: Quality of Life-Short-Form 36; TePs: Pressure Algometry Measurements of Tender Point. VAS: Visual Analog Scale. VASs: Visual Analogue Scale.

Two studies investigated the effects of oral nabilone, a synthetic cannabinoid in FM patients. One study [22] was a randomized, double-blinded, active-control, equivalency crossover trial to compare nabilone to amitriptyline, before bedtime in patients with FM reporting chronic insomnia. Twenty-nine subjects received each drug for two weeks with a two-week washout period and were assessed for sleep quality, pain, quality of life, and adverse events. Nabilone was effective in improving sleep in patients with FM and was well tolerated, which may be considered an alternative strategy to amitriptyline. The effects of nabilone on pain, mood, and quality of life were similar to those seen with amitriptyline. Adverse effects were more common with nabilone, particularly drowsiness and dizziness, as are common for other cannabinoids, although global satisfaction with both drugs was similar.

One randomized, double-blinded, placebo-controlled trial [21] aimed at determining the benefit of nabilone in pain management and life quality improvement in FM patients. Forty patients were randomized and received nabilone, from 
$0.5 \mathrm{mg}$ at bedtime to $1 \mathrm{mg}$ over 4 weeks or a corresponding placebo, and after four weeks were reassessed for pain and the number of tender points. There were significant decreases in pain and anxiety in the nabilone-treated group in four weeks. There were no significant improvements in the placebo group. Nabilone appears to be a beneficial, well-tolerated treatment option for FM patients, with significant benefits in pain relief and functional improvement.

The O24 Pain Neutralizer, a natural pain relief solution which contains camphor oil (white) (Japan), eucalyptus oil (Australia), Aloe vera oil (Mexico), peppermint oil (India), rosemary oil (Spain), lemon oil (USA), and orange oil (USA), was investigated by two studies for its possible effects in FM patients. The study of Rutledge and Jones (2007) [20], a randomized clinical trial, compared $\mathrm{O} 24$ with sham oil combined with exercise, and 43 women were trained in O24 application before exercise, at bedtime on exercise days. After a twelveweek period, the patients were assessed for exercise volume, pain, physical performance, and physical function. There was no significant difference in exercise volume between women using O24 as compared with that using sham oil after twelve weeks. The authors concluded that increases in physical function found, while not significant, may be attributable to the exercise regimen or to the interaction of the oils and exercise regimen.

One double-blinded placebo-controlled trial study compared $\mathrm{O} 24$ with placebo [16], and 153 subjects were randomized and trained in O24 application every four hours as needed for pain, or placebo oils (peppermint oil) identical in smell and appearance, and active oils were supplied to the other half. After four weeks, patients were assessed for pain, tender point, and strength. With topical O24 over the placebo, improvements were noted in the visual analog scale night pain rating.

Meta050, a proprietary standardized combination of reduced iso-alpha acids from hops, rosemary extract, and oleanolic acid, were investigated for their possible effects on pain in patients with rheumatic disease: osteoarthritis, rheumatoid arthritis, and FM [18]. Fifty-four patients received $440 \mathrm{mg}$ of Meta050 three times a day for four weeks, which was changed to $880 \mathrm{mg}$ twice a day for the subsequent four weeks in the majority of patients. We analyzed pain and specific symptoms by means of the Abridged Arthritis Impact Measurement Scale (AIMS2) and the Fibromyalgia Impact Questionnaire (FIQ). FM patients demonstrated some improvement on pain; however, the decrease in pain did not reach significance within four weeks. No significant difference was observed in grip strength on these subjects, either. In general, pain and stiffness were moderately improved, but only after eight weeks on the supplement.

One open clinical trial was undertaken to measure the subjective effects of coenzyme Q10 combined with a Ginkgo biloba extract in volunteer subjects with clinically diagnosed FM [17]. Thus, 23 subjects received oral doses of $200 \mathrm{mg}$ coenzyme Q10 combined with 200 mg Ginkgo biloba extract. After twelve weeks, patients were assessed for quality of life; $68 \%$ of those who completed the trial expressed the view that they would like to continue with treatments. The overall subjective views of the patients, regardless of quality of life scores, were that the majority (64\%) felt the treatment was of some benefit.

3.4. Quality of Evidence. The methodological quality of all included trials was evaluated by using JADAD scale and two studies were rated as good quality [15, 21]; four studies, moderate $[16,19,20,22]$; and two studies, low $[17,18]$.

\section{Discussion}

Considerable efforts have been made to discover new analgesic agents with increased efficacy and fewer side effects. Therefore, our review aimed at investigating the effects of MP or RNP in FM patients, based on an analysis of eight RCTs, trying to propose new possibilities that can offer secure relief in symptoms. Interestingly, the results found indicated similar pharmacological effects between related products or MP natural and standard drugs used in controlling symptoms of FM. When compared with placebo, MP or RNP demonstrated positive effects in pain relief, quality of life, anxiety, sleep disruption, and physical function. The clinical challenge persists because there is not yet a specific target with therapeutic applicability.

This challenge also affects the drugs that are already part of the clinical management of FM. Although drug therapy is very broad and added the clinical approach of these patients, currently, duloxetine, pregabalin, and milnacipran are the only ones approved by the FDA for the treatment of FM [29]. The mechanisms of action of pregabalin, duloxetine, and milnacipran are related to the pathophysiology of FM; however, these therapeutic agents are not effective for all patients with FM. A recent study by Katz et al. suggests that the diagnostic criteria for fibromyalgia may be partly responsible for the fact that there is currently no gold standard for the diagnosis and treatment of FM [30].

In this review, we found two studies involving capsaicin in the treatment of FM $[15,19]$. Capsaicin, the main active capsaicinoid ingredient of chili peppers (Capsicum spp.), an agonist of the transient receptor potential vanilloid 1 (TRPV1) receptor [31], is highly expressed on nociceptors [32-34], which causes an initial excitation of the neurons and a period of enhanced sensitivity. This selective stimulation of afferent $\mathrm{C}$ fibers and the release of substance P (SP) are followed by a refractory period with reduced sensitivity. Repeated applications lead to persistent desensitization possibly due to depletion of SP at nervous afferent endings and transiently decrease the density of nervous fibers on the skin [35]. Repeated applications lead to a long-lasting desensitization towards pain due to the increase in pain threshold and a flare on the skin in FM patients, suggesting an increased activity of polymodal nociceptors.

Recent evidence demonstrates that the vanilloid receptor, stimulated by capsaicin or by endocannabinoids in ventral periaqueductal gray (vPAG), induces analgesia [36]. This analgesic effect is associated with increased release of glutamate and activation of rostral ventromedial medulla cells. The activation of the descending nociceptive stimulation of this receptor in the vPAG may be a new strategy for producing 
analgesia [37, 38]. Given the benefits of using capsaicin, which was also approved by the FDA for the management of neuropathic pain in November 2009 [32], the adverse effects are manageable and do not constitute a limitation to its use, but a motivation of new formulations that may have better applicability and acceptance.

Although pain is the primary chronic symptom, disturbed sleep is also a major symptom of patients with FM; patients report difficulty falling asleep, significantly more nighttime awakenings, and unrefreshing sleep [39, 40]. Sleep problems have been related to both depression and pain among patients with FMS in some studies [38, 40] and insomnia has been frequently reported in FM patients [41].

Endogenous cannabinoids have been postulated to have an effect on normal sleep induction [42]. Nabilone, a synthetic cannabinoid, has been observed in a small case series to improve sleep in patients with chronic pain [41]. Researchers conducted clinical trial of cannabinoids for other chronic pain disorders and have reported benefits on sleep as secondary outcome [41]. One of the studies included in this review [22] confirmed the indirect positive effect on sleep as it was observed that both synthetic cannabinoid nabilone and amitriptyline, a tricyclic antidepressant, had a favorable effect on sleep in patients with FM, with nabilone showing higher overall superiority than amitriptyline in relation to the quality of sleep.

Although there are no specific clinical studies on the use of cannabinoid receptor agonists for symptomatic relief of FM, some findings support their therapeutic potential due to their anti-inflammatory, analgesic, and sedative properties [42]. The analgesic benefits of cannabinoids in the treatment of acute and chronic pain have already been suggested [43], and according to another study that was assessed, pain and anxiety symptoms were attenuated using cannabinoid [21]. This benefit was probably secondary to a clinical endocannabinoid deficiency in FM patients as has been suggested [41] or the synergistic relationship with endogenous opioids [44]. Behavioral studies provide evidence that both CB1 and $\mathrm{CB} 2$ receptors can contribute to muscular antinociception and, interestingly, suggest that the local administration of CB agonists could be a new and useful pharmacological strategy in the treatment of muscular pain, avoiding adverse effects induced by systemic administration [45].

A pilot RCT study performed by Traitses et al. (2007) [46] suggests that FM patients may be effectively and safely managed for pain with topical O24. Two studies reported benefits after treatment with $\mathrm{O} 24$, a topical pain relief agent $[16,20]$. Compared to other topical products, O24 is unique in incorporating well-studied botanicals without alcohol, glycerin, synthetics, or preservatives. Each active ingredient of O24 (camphor oil, eucalyptus oil, aloe vera oil, peppermint oil, rosemary oil, and lemon and orange oils), has been studied for pain [47-49] and the primary mode of action is a counterirritant for pain sensation and the local effects include inhibition of pain transmitters such as bradykinin, histamine, and prostaglandins [50].

Another RCT used the same agent to verify the viability of topical $\mathrm{O} 24$ in FM patients, associated with exercise. In previous studies, da Costa et al. found that pain and fatigue decrease in activity for subjects with FM and chronic fatigue syndrome, rather than bouts of exercise leading to pain and fatigue [51]. Muscle stretching generates a positive impact in the treatment of fibromyalgia, improving pain, stiffness, and quality of sleep [52], and the aerobic activities were considered effective, including benefits months after the end of treatment [53]. Thus, a double-blind RCT that assessed the joint action of $\mathrm{O} 24$ associated with an exercise program [20] observed benefits in physical function and pain relief in FM patients which enabled greater adherence to exercise program.

The prevalence of psychological abnormalities, particularly depression, is high among FM patients [54-56]. Meta 050 , a tablet containing $440 \mathrm{mg}$ of a proprietary formulation of RIAA (as magnesium salt from Humulus lupulus cone extract), standardized rosemary extract (Rosmarinus officinalis) and oleanolic acid (from Olea europaea olive leaf extract). Rosemary, Rosmarinus officinalis L., has many therapeutic applications in popular medicine to cure or manage a wide range of diseases, including depression [57]. The oleanolic acid (OA) is a pentacyclic triterpene that pertains to oleanane series naturally found in various medicinal herbs traditionally used for anti-inflammatory, analgesic, hepatoprotective, and cardiotonic effects [58]. The antinociceptive effect of OA appears to involve endogenous opioids as it was blocked in mice pretreated with naloxone, a nonselective opioid antagonist; this supports the notion that compounds like OA might be useful as pain relievers [59]. The study assessed in this review [18] supports previous conclusions and suggests that Meta050 can offer moderate benefits for the management of pain and depression.

Given the vast symptomatology that is present in FM, the quality of life could not change coursing with large negative impact on the lives of these patients [60, 61]. Moreover, several studies show that there are significant changes in the balance oxidant/antioxidant in triggering the FM, with a significant increase in the number of free radicals [62-64]. Some FMS patients with muscle pains have found benefit from coenzyme Q10, while others with central nervous system symptoms have found benefit from Ginkgo biloba extract. Coenzyme Q10 is essential for normal muscle activity and a deficiency in this coenzyme is thought to impair function [65]. Ginkgo biloba extract can improve vascular function in both muscle and brain [66]. As both of these agents are antioxidants and free radical scavengers, it is possible that the benefit demonstrated in a study assessed in this review [17] may be due, at least in part, to an antioxidant activity.

The methodological limitations of the studies reported in this systematic literature review included small sample sizes, lack of blinding, and differences in treatment as well as in the severity of disease of the participants, are also factors that potentially introduce difficulties in the analysis, as large differences in treatment effects can be expected. Although strong efforts were made to retrieve all RCTs on the subject, we cannot be absolutely certain that we succeeded.

The results also may have been compromised by heterogeneity. The chemical composition of the weed grown naturally varies according to weather conditions, harvest time, 
storage conditions, and so forth. This variability can result in significant differences in pharmacological activity, making it difficult to standardize them botanically [67]. Studies using standard formulations also show interesting activity that was isolated from each of the components of the formula. Due to the limited number of RCTs included, we cannot draw definitive conclusions about MP or RNP in the treatment of patients with FM; however, the results allow us to believe in the potential of plants as biological targets to be studied in order to achieve better therapeutic action and fewer adverse effects.

\section{Conclusion}

Based on the current review, it is unclear whether MP or $\mathrm{RNP}$ is effective in treating fibromyalgia. However, it was noted that these therapies are promising in the treatment of rheumatic conditions as chronic fibromyalgia. More studies with adequate methodological quality in order to investigate the efficacy and safety of MP or RNP for fibromyalgia are needed.

$\begin{array}{ll}\text { Abbreviations } \\ \text { BPI: } & \text { Brief Pain Inventory } \\ \text { BMI: } & \text { Body Mass Index } \\ \text { CAM: } & \text { Complementary and alternative } \\ & \text { medicine } \\ \text { FDA: } & \text { Food and Drug Administration } \\ \text { FDK: } & \text { Force Dial-Standard Pressure } \\ & \text { Algometry } \\ \text { FIQ: } & \text { Fibromyalgia Impact Questionnaire } \\ \text { FM: } & \text { Fibromyalgia } \\ \text { FSS: } & \text { Fatigue Severity Scale } \\ \text { GSI: } & \text { Global Severe Index } \\ \text { HAD: } & \text { Hospital Anxiety and Depression Scale } \\ \text { HGS: } & \text { Handgrip Strength } \\ \text { ISI: } & \text { Insomnia Severity Index } \\ \text { LSEQ: } & \text { The Leeds Sleep Evaluation } \\ & \text { Questionnaire } \\ \text { MCS: } & \text { Mental Function Score } \\ \text { MPs: } & \text { Medicinal plants } \\ \text { MPI: } & \text { Multidisciplinary Pain Inventory } \\ \text { MPQ: } & \text { McGill Pain Questionnaire } \\ \text { NSAIDs: } & \text { Anti-inflammatory nonsteroidal drugs } \\ \text { OA: } & \text { Oleanolic acid } \\ \text { PCS: } & \text { Physical Function Score } \\ \text { PHN: } & \text { Postherpetic Neuralgia } \\ \text { PSQI: } & \text { Pittsburgh Sleep Quality Index } \\ \text { QLS: } & \text { Quality of Life Questionnaire } \\ \text { RCTs: } & \text { Randomized controlled trials } \\ \text { RNPs: } & \text { Related natural products } \\ \text { SCPV: } & \text { Ventral periaqueductal Gray } \\ \text { SF 36: } & \text { Short Form 36 Health Survey } \\ \text { SRs: } & \text { Systematic reviews } \\ \text { TePs: } & \text { Pressure Algometry Measurements of } \\ & \text { Tender Point } \\ & \text { Visual Analog Scale } \\ \text { Ventral periaqueductal gray. } \\ \end{array}$

\section{Conflict of Interests}

The authors report no conflict of interests.

\section{Acknowledgment}

This work was supported by Grants from the FAPITECSE/Brazil (01790/2011-8/PRONEM/2011) and CNPq/Brazil (305783/2010-6 and 470774/2011-8). Simone S. Nascimento has scholarship from Núcleo de Pós-Graduação em Ciências da Saúde (Federal University of Sergipe/Brazil). The authors also thank Abilio Antonio Borghi for the English review of the paper.

\section{References}

[1] S. R. Pillemer, L. A. Bradley, L. J. Crofford, H. Moldofsky, and G. P. Chrousos, "The neuroscience and endocrinology of fibromyalgia," Arthritis and Rheumatism, vol. 40, no. 11, pp. 19281939, 1997.

[2] R. Staud, C. J. Vierck, R. L. Cannon, A. P. Mauderli, and D. D. Price, "Abnormal sensitization and temporal summation of second pain (wind-up) in patients with fibromyalgia syndrome," Pain, vol. 91, no. 1-2, pp. 165-175, 2001.

[3] R. Staud, C. J. Vierck, M. E. Robinson, and D. D. Price, "Effects of the N-methyl-D-aspartate receptor antagonist dextromethorphan on temporal summation of pain are similar in fibromyalgia patients and normal control subjects," Journal of Pain, vol. 6, no. 5, pp. 323-332, 2005.

[4] L. A. Nielsen and K. G. Henriksson, "Pathophysiological mechanisms in chronic musculoskeletal pain (fibromyalgia): the role of central and peripheral sensitization and pain disinhibition," Best Practice and Research: Clinical Rheumatology, vol. 21, no. 3, pp. 465-480, 2007.

[5] D. Dadabhoy, L. J. Crofford, M. Spaeth, I. J. Russell, and D. J. Clauw, "Biology and therapy of fibromyalgia. Evidence-based biomarkers for fibromyalgia syndrome," Arthritis Research and Therapy, vol. 10, no. 4, article 211, 2008.

[6] R. A. Dionne, "Pharmacologic treatments for temporomandibular disorders," Oral Surgery, Oral Medicine, Oral Pathology, Oral Radiology, and Endodontics, vol. 83, no. 1, pp. 134-142, 1997.

[7] D. Xu, V. Trajkovic, D. Hunter et al., "IL-18 induces the differentiation of Th1 or Th2 cells depending upon cytokine milieu and genetic background," European Journal of Immunology, vol. 30, no. 11, pp. 3147-3156, 2000.

[8] D. J. Clauw, L. M. Arnold, and B. H. McCarberg, "The science of fibromyalgia," Mayo Clinic Proceedings, vol. 86, no. 9, pp. 907911, 2011.

[9] K. Srinivasan, S. Muruganandan, J. Lal, S. Chandra, S. K. Tandan, and V. Ravi Prakash, "Evaluation of anti-inflammatory activity of Pongamia pinnata leaves in rats," Journal of Ethnopharmacology, vol. 78, no. 2-3, pp. 151-157, 2001.

[10] A. M. Venâncio, M. Marchioro, C. S. Estavam et al., "Ocimum basilicum leaf essential oil and (-)-linalool reduce orofacial nociception in rodents: a behavioral and electrophysiological approach," Revista Brasileira de Farmacognosia, vol. 21, no. 6, pp. 1043-1051, 2011.

[11] D. Butler, "Translational research: crossing the valley of death," Nature, vol. 453, no. 7197, pp. 840-842, 2008.

[12] S. C. H. Vieira, S. Sólon, M. C. Vieira, and N. A. Heredia Zárate, "Levantamento de fitoterápicos manipulados em farmácias 
magistrais de Dourados-MS," Revista Brasileira de Farmacognosia, vol. 20, no. 1, pp. 28-34, 2010.

[13] J. B. Calixto, A. Beirith, J. Ferreira, A. R. Santos, V. C. Filho, and R. A. Yunes, "Naturally occurring antinociceptive substances from plants," Phytotherapy Research, vol. 14, no. 6, pp. 401-418, 2000.

[14] J. Wang and X. Xiong, "Outcome measures of Chinese herbal medicine for hypertension: an overview of systematic reviews," Evidence-Based Complementary and Alternative Medicine, vol. 2012, Article ID 697237, 7 pages, 2012.

[15] B. Casanueva, B. Rodero, C. Quintial, J. Llorca, and M. A. González-Gay, "Short-term efficacy of topical capsaicin therapy in severely affected fibromyalgia patients," Rheumatology International, 2012.

[16] G. D. Ko, A. Hum, G. Traitses, and D. Berbrayer, "Effects of topical O24 essential oils on patients with fibromyalgia syndrome: a randomized, placebo controlled pilot study," Journal of Musculoskeletal Pain, vol. 15, no. 1, pp. 11-19, 2007.

[17] R. E. Lister, "An open, pilot study to evaluate the potential benefits of coenzyme Q10 combined with Ginkgo biloba extract in fibromyalgia syndrome," Journal of International Medical Research, vol. 30, no. 2, pp. 195-199, 2002.

[18] D. Lukaczer, G. Darland, M. Tripp et al., "A pilot trial evaluating Meta050, a proprietary combination of reduced iso-alpha acids, rosemary extract and oleanolic acid in patients with arthritis and fibromyalgia," Phytotherapy Research, vol. 19, no. 10, pp. 864-869, 2005.

[19] D. J. McCarty, M. Csuka, G. McCarthy, and D. Trotter, “Treatment of pain due to fibromyalgia with topical capsaicin: a pilot study," Seminars in Arthritis and Rheumatism, vol. 23, supplement 3, pp. 41-47, 1994.

[20] D. N. Rutledge and C. J. Jones, "Effects of topical essential oil on exercise volume after a 12-week exercise program for women with fibromyalgia: a pilot study," Journal of Alternative and Complementary Medicine, vol. 13, no. 10, pp. 1099-1106, 2007.

[21] R. Q. Skrabek, L. Galimova, K. Ethans, and D. Perry, "Nabilone for the treatment of pain in fibromyalgia," Journal of Pain, vol. 9, no. 2, pp. 164-173, 2008.

[22] M. A. Ware, M. Fitzcharles, L. Joseph, and Y. Shir, "The effects of nabilone on sleep in fibromyalgia: results of a randomized controlled trial," Anesthesia and Analgesia, vol. 110, no. 2, pp. 604-610, 2010.

[23] A. R. Jadad, R. A. Moore, D. Carroll et al., "Assessing the quality of reports of randomized clinical trials: is blinding necessary?" Controlled Clinical Trials, vol. 17, no. 1, pp. 1-12, 1996.

[24] J. J. Shuster, "Review: cochrane handbook for systematic reviews for interventions, Version 5.1.0, published 3/2011. Julian P.T. Higgins and Sally Green, Editors," Research Synthesis Methods, vol. 2, no. 2, pp. 126-130, 2011.

[25] F. Wolfe, D. J. Clauw, M. Fitzcharles et al., "The American College of Rheumatology preliminary diagnostic criteria for fibromyalgia and measurement of symptom severity," Arthritis Care and Research, vol. 62, no. 5, pp. 600-610, 2010.

[26] Y. Chong and B. Ng, "Clinical aspects and management of fibromyalgia syndrome," Annals of the Academy of Medicine Singapore, vol. 38, no. 11, pp. 967-973, 2009.

[27] D. Buskila, "Developments in the scientific and clinical understanding of fibromyalgia," Arthritis Research and Therapy, vol. 11, no. 5, article 242, 2009.

[28] S. Silverman, A. Sadosky, C. Evans, Y. Yeh, J. M. J. Alvir, and G. Zlateva, "Toward characterization and definition of fibro7myalgia severity," BMC Musculoskeletal Disorders, vol. 11, no. 1 , article $66,2010$.

[29] M. A. Fitzcharles, P. A. Ste-Marie, D. L. Goldenberg et al., "2012 Canadian Guidelines for the diagnosis and management of fibromyalgia syndrome".

[30] R. S. Katz, F. Wolfe, and K. Michaud, "Fibromyalgia diagnosis: a comparison of clinical, survey, and American College of Rheumatology criteria," Arthritis and Rheumatism, vol. 54, no. 1, pp. 169-176, 2006.

[31] M. J. Caterina, M. A. Schumacher, M. Tominaga, T. A. Rosen, J. D. Levine, and D. Julius, "The capsaicin receptor: a heatactivated ion channel in the pain pathway," Nature, vol. 389, no. 6653, pp. 816-824, 1997.

[32] C. Noto, M. Pappagallo, and A. Szallasi, "NGX-4010, a highconcentration capsaicin dermal patch for lasting relief of peripheral neuropathic pain," Current Opinion in Investigational Drugs, vol. 10, no. 7, pp. 702-710, 2009.

[33] A. Szallasi, "Autoradiographic visualization and pharmacological characterization of vanilloid (capsaicin) receptors in several species, including man," Acta Physiologica Scandinavica, Supplement, vol. 155, no. 629, pp. 1-68, 1995.

[34] A. Szallasi and P. M. Blumberg, "Vanilloid (Capsaicin) receptors and mechanisms," Pharmacological Reviews, vol. 51, no. 2, pp. 159-211, 1999.

[35] M. Nolano, D. A. Simone, G. Wendelschafer-Crabb, T. Johnson, E. Hazen, and W. R. Kennedy, "Topical capsaicin in humans: parallel loss of epidermal nerve fibers and pain sensation," Pain, vol. 81, no. 1-2, pp. 135-145, 1999.

[36] E. Palazzo, F. Rossi, and S. Maione, "Role of TRPV1 receptors in descending modulation of pain," Molecular and Cellular Endocrinology, vol. 286, no. 1-2, pp. S79-S83, 2008.

[37] S. Maione, T. Bisogno, V. de Novellis et al., "Elevation of endocannabinoid levels in the ventrolateral periaqueductal grey through inhibition of fatty acid amide hydrolase affects descending nociceptive pathways via both cannabinoid receptor type 1 and transient receptor potential vanilloid type-1 receptors," Journal of Pharmacology and Experimental Therapeutics, vol. 316, no. 3, pp. 969-982, 2006.

[38] Y. Jia, R. L. McLeod, and J. A. Hey, "TRPV1 receptor: a target for the treatment of pain, cough, airway disease and urinary incontinence," Drug News and Perspectives, vol. 18, no. 3, pp. 165-171, 2005.

[39] S. M. Bigatti, A. M. Hernandez, T. A. Cronan, and K. L. Rand, "Sleep disturbances in fibromyalgia syndrome: relationship to pain and depression," Arthritis Care and Research, vol. 59, no. 7, pp. 961-967, 2008.

[40] S. M. Harding, "Sleep in fibromyalgia patients: subjective and objective findings," The American Journal of the Medical Sciences, vol. 315, no. 6, pp. 367-376, 1998.

[41] E. B. Russo, "Taming THC: potential cannabis synergy and phytocannabinoid-terpenoid entourage effects," British Journal of Pharmacology, vol. 163, no. 7, pp. 1344-1364, 2011.

[42] E. B. Russo, "Clinical endocannabinoid deficiency (CECD): can this concept explain therapeutic benefits of cannabis in migraine, fibromyalgia, irritable bowel syndrome and other treatment-resistant conditions?" Neuroendocrinology Letters, vol. 25, no. 1-2, pp. 31-39, 2004.

[43] B. F. Cravatt and A. H. Lichtman, "The endogenous cannabinoid system and its role in nociceptive behavior," Journal of Neurobiology, vol. 61, no. 1, pp. 149-160, 2004. 
[44] G. Pugh Jr., D. J. Mason Jr., V. Combs, and S. P. Welch, "Involvement of dynorphin B in the antinociceptive effects of the cannabinoid CP55,940 in the spinal cord," Journal of Pharmacology and Experimental Therapeutics, vol. 281, no. 2, pp. 730-737, 1997.

[45] E. M. Sanchez Robles, A. Bagues Arias, and M. I. Martin Fontelles, "Cannabinoids and muscular pain. Effectiveness of the local administration in rat," European Journal of Pain, vol. 16, no. 8, pp. 1116-1127, 2012.

[46] G. Traitses, A. Hum, G. Ko et al., "435 topical essential oils for fibromyalgia neuropathic pain: a randomized controlled trial," European Journal of Pain, vol. 11, supplement 1, pp. S192-S193, 2007.

[47] M. Cohen, R. Wolfe, T. Mai, and D. Lewis, "A randomized, double blind, placebo controlled trial of a topical cream containing glucosamine sulfate, chondroitin sulfate, and camphor for osteoarthritis of the knee," Journal of Rheumatology, vol. 30, no. 3, pp. 523-528, 2003.

[48] H. Gobel, G. Schmidt, and D. Soyka, "Effect of peppermint and eucalyptus oil preparations on neurophysiological and experimental algesimetric headache parameters," Cephalalgia, vol. 14, no. 3, pp. 228-234, 1994.

[49] R. H. Davis, K. Y. Rosenthal, L. R. Cesario, and G. A. Rouw, "Processed Aloe vera administered topically inhibits inflammation," Journal of the American Podiatric Medical Association, vol. 79, no. 8, pp. 395-397, 1989.

[50] C. Hong and F. G. Shellock, "Effects of a topically applied counterirritant (Eucalyptamint) on cutaneous blood flow and on skin and muscle temperatures. A placebo-controlled study," American Journal of Physical Medicine and Rehabilitation, vol. 70, no. 1, pp. 29-33, 1991.

[51] D. da Costa, M. Abrahamowicz, I. Lowensteyn et al., "A randomized clinical trial of an individualized home-based exercise programme for women with fibromyalgia," Rheumatology, vol. 44, no. 11, pp. 1422-1427, 2005.

[52] L. Bressan, L. Matsutani, A. Assumpção et al., "Efeitos do alongamento muscular e condicionamento físico no tratamento fisioterápico de pacientes com fibromialgia," Revista Brasileira de Fisioterapia, vol. 12, pp. 88-93, 2008.

[53] K. D. Jones, D. Adams, K. Winters-Stone, and C. S. Burckhardt, "A comprehensive review of 46 exercise treatment studies in fibromyalgia (1988-2005)," Health and Quality of Life Outcomes, vol. 4, no. 1, article 67, 2006.

[54] R. Çeliker and P. Borman, "Fibromyalgia versus rheumatoid arthritis: a comparison of psychological disturbance and life satisfaction," Journal of Musculoskeletal Pain, vol. 9, no. 1, pp. 35-45, 2001.

[55] J. I. Hudson and H. G. Pope Jr., "The relationship between fibromyalgia and major depressive disorder," Rheumatic Disease Clinics of North America, vol. 22, no. 2, pp. 285-303, 1996.

[56] C. Pae, P. Luyten, D. M. Marks et al., "The relationship between fibromyalgia and major depressive disorder: a comprehensive review," Current Medical Research and Opinion, vol. 24, no. 8, pp. 2359-2371, 2008.

[57] D. G. Machado, L. E. B. Bettio, M. P. Cunha et al., "Antidepressant-like effect of the extract of Rosmarinus officinalis in mice: involvement of the monoaminergic system," Progress in Neuro-Psychopharmacology and Biological Psychiatry, vol. 33, no. 4, pp. 642-650, 2009.

[58] L. Jie, "Pharmacology of oleanolic acid and ursolic acid," Journal of Ethnopharmacology, vol. 49, no. 2-1, pp. 57-68, 1995.

[59] J. L. Maia, R. C. P. Lima-Júnior, C. M. Melo et al., "Oleanolic acid, a pentacyclic triterpene attenuates capsaicin-induced nociception in mice: possible mechanisms," Pharmacological Research, vol. 54, no. 4, pp. 282-286, 2006.

[60] H. S. J. Picavet and N. Hoeymans, "Health related quality of life in multiple musculoskeletal diseases: SF-36 and EQ-5D in the DMC3 study," Annals of the Rheumatic Diseases, vol. 63, no. 6, pp. 723-729, 2004.

[61] A. P. Marques, A. M. Barsante Santos, A. Assumpção, L. A. Matsutani, L. V. Lage, and C. A. B. Pereira, "Validation of the Brazilian version of the Fibromyalgia Impact Questionnaire (FIQ)," Revista Brasileira de Reumatologia, vol. 46, no. 1, pp. 2431, 2006.

[62] S. Bagis, L. Tamer, G. Sahin et al., "Free radicals and antioxidants in primary fibromyalgia: an oxidative stress disorder?" Rheumatology International, vol. 25, no. 3, pp. 188-190, 2005.

[63] G. Berti, C. Schallenberger, L. Haas et al., "Hidroterapia aplicada ao tratamento da fibromialgia: avaliação clínica e laboratorial de pacientes atendidos no Centro Universitário Feevale," Novo Hamburgo (RS), 2008.

[64] S. Ozgocmen, H. Ozyurt, S. Sogut, and O. Akyol, "Current concepts in the pathophysiology of fibromyalgia: the potential role of oxidative stress and nitric oxide," Rheumatology International, vol. 26, no. 7, pp. 585-597, 2006.

[65] P. Zeppilli, B. Merlino, A. de Luca et al., "Influence of coenzyme Q10 on physical work capacity in athletes, sedentary people and patients with mitochondrial disease," in Blomedical and Clinical Aspects of Coenzyme Q10, vol. 6, 1991.

[66] J. Kleijnen and P. Knipschild, "Ginkgo biloba," The Lancet, vol. 340, no. 8828, pp. 1136-1139, 1992.

[67] F. Firenzuoli and L. Gori, "Herbal medicine today: clinical and research issues," Evidence-Based Complementary and Alternative Medicine, vol. 4, supplement 1, pp. 37-40, 2007. 


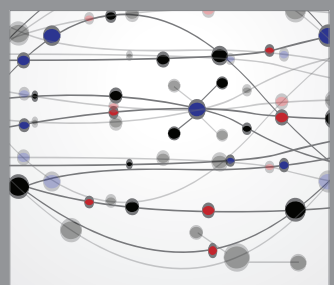

The Scientific World Journal
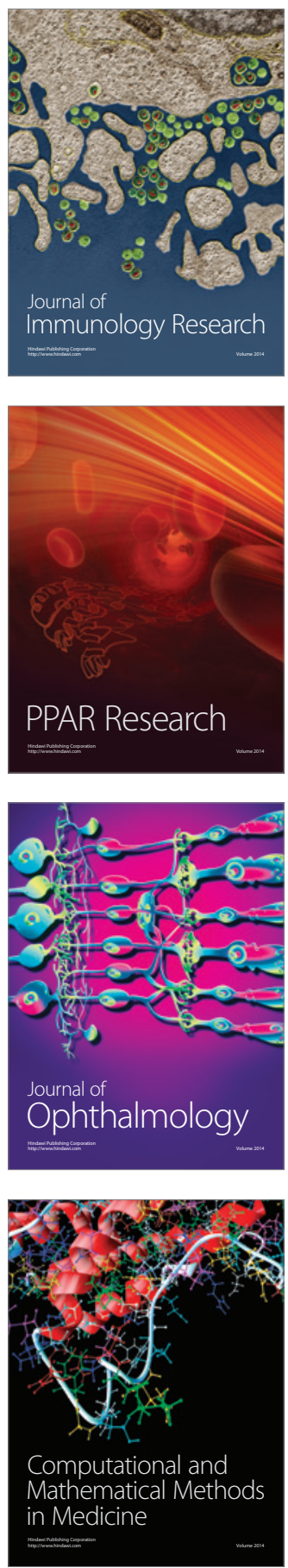

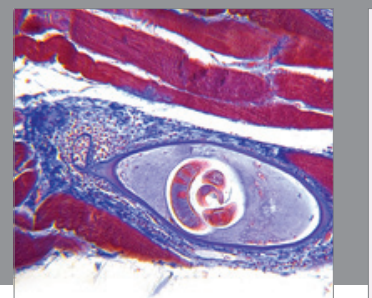

Gastroenterology

Research and Practice
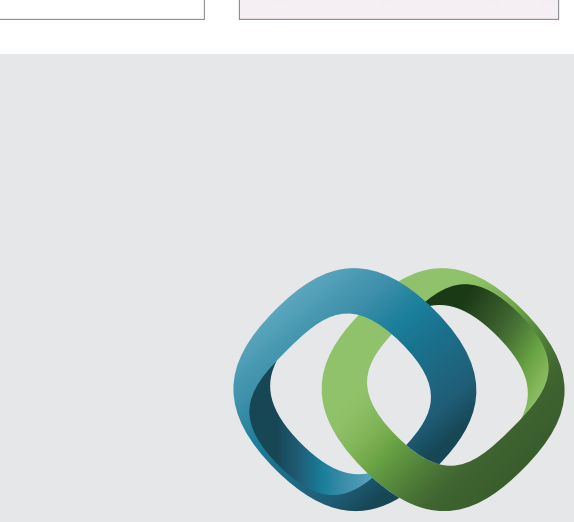

\section{Hindawi}

Submit your manuscripts at

http://www.hindawi.com
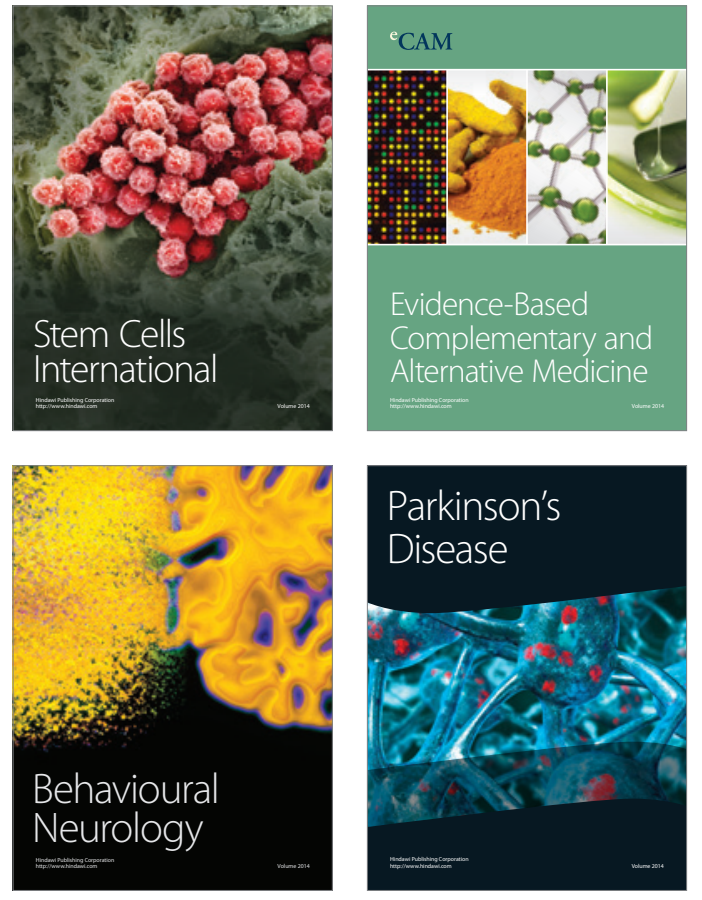
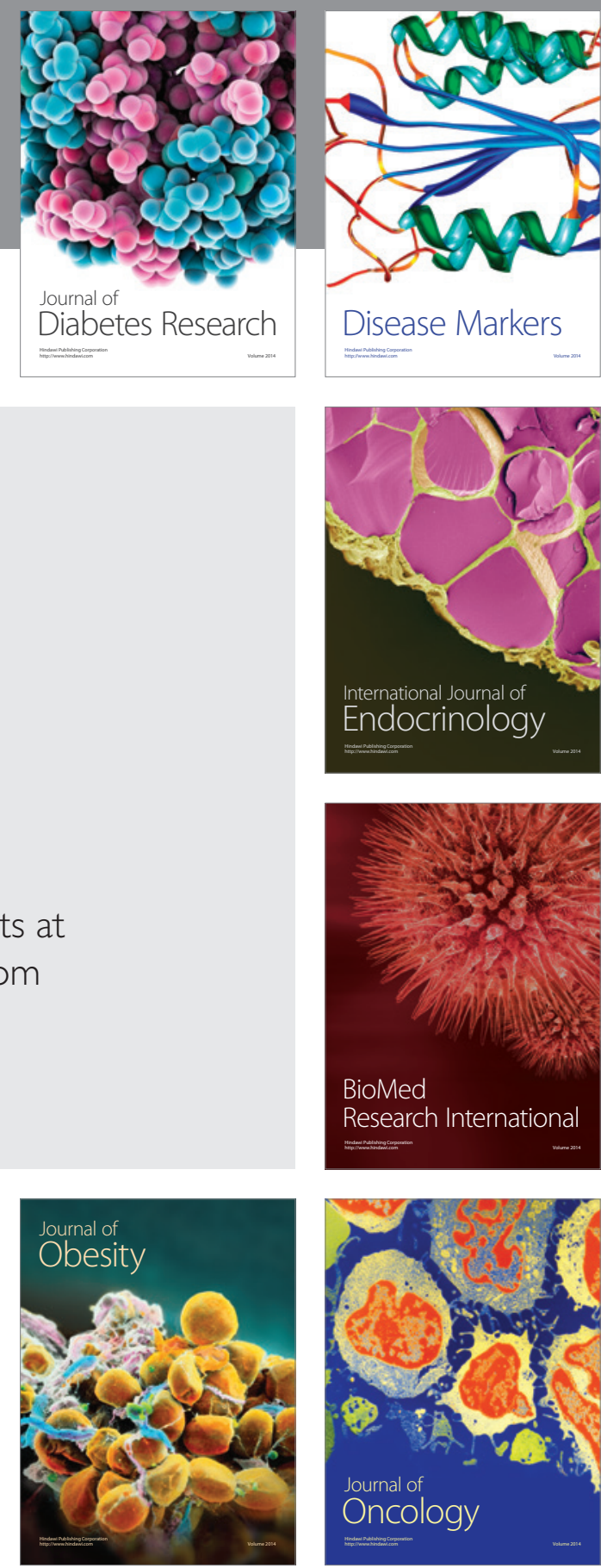

Disease Markers
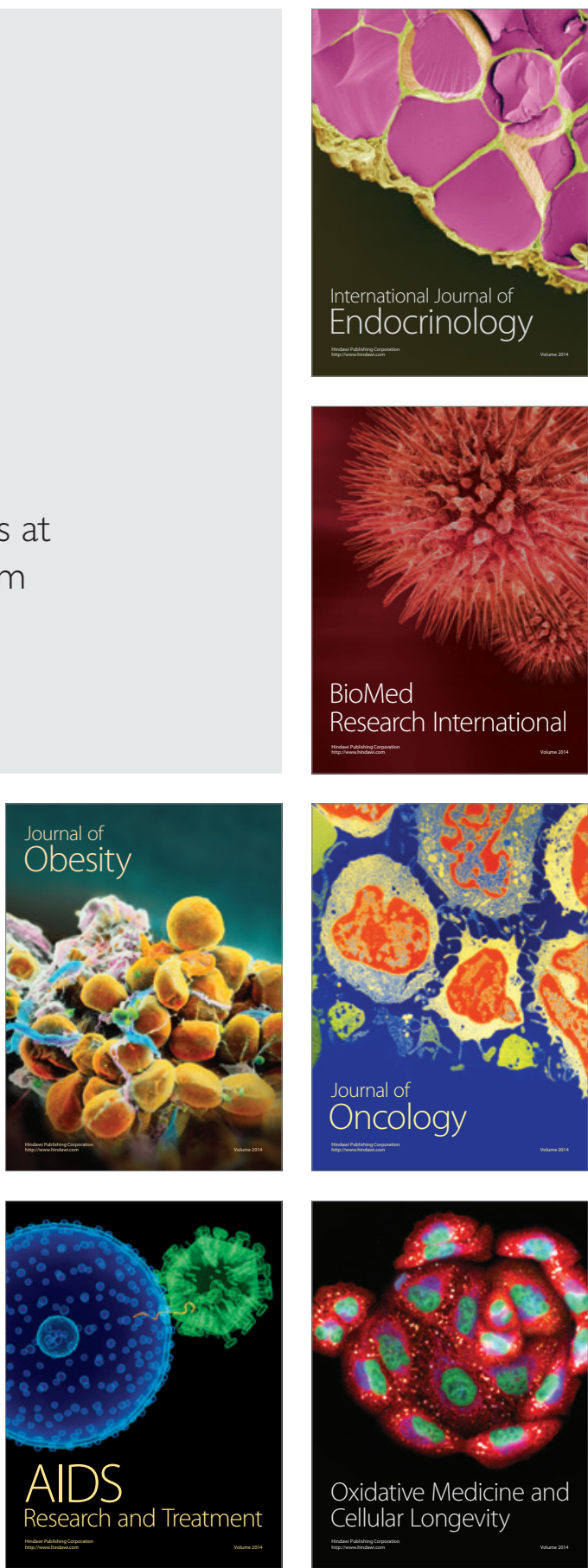